\title{
Música de boy para un pensar por venir. Nietzsche y la música del último siglo: una aproximación
}

\author{
JOSÉ LUIS LÓPEZ LÓPEZ
}

Casi todos los términos del título que antecede están amenazados por la confusión. Conviene, aunque brevemente, apuntar de modo inmediato al sentido en que serán usados aquí, para descartar, en lo posible, algún que otro malentendido.

Música de hoy: bajo la rúbrica del 'presente histórico' puede considerarse 'de hoy' la música (clásica, culta o artística, según quiera llamársela) que, tras el «desesperado 'adiós' de Mahler al esplendor clásico» ${ }^{1}$, se inaugura en 1894 , cuando se ejecutó por primera vez la obra de Debussy Prèlude à l'après-midi d'un faune (compuesta a partir de la famosa égloga de Mallarmé, a la que «pretendía ilustrar con total libertad»). Algunos comprendieron entonces lo que ya se acepta comúnmente: que con esta pieza se estaba instaurando, como diría muchos años después Pierre Boulez, «una nueva respiración del arte musical» 2 . Por 'música de hoy' entendemos, pues, la que se extiende desde esa inauguración hasta el año que corre: por tanto, el último siglo al que alude el subtítulo debe entenderse ampliamente, digamos por precisar que desde 1894 hasta comienzos de 2002. Sin embargo, hay que hacer una doble salvedad (general, y más o menos difícil de objetivar

1 E. Lisciani-Petrini, Tierra en blanco. Música y pensamiento a inicios del siglo XX, tr. C. del Olmo y C. Rendueles, Akal (Col. Hipecu), Madrid, 1999, p. 22.

2 Ibid., pp. 24-25. 
en cada caso particular): primera, que no siempre están claros los límites estilísticos entre lo que es música 'clásica' y otras músicas; segunda, que no toda la música (aceptemos que 'clásica') compuesta dentro de ese período temporal puede considerarse música de hoy, sino mera recreación o reproducción de la música 'anterior'.

La segunda salvedad es difícil de elucidar y tiene que ser eludida, salvo excepción, en un artículo como éste. La primera, por el contrario, no puede ser pasada por alto, ya que la música 'de consumo', si aceptamos esta denominación por oposición a la de música 'culta’3, ofrece dos aspectos que no se pueden silenciar: uno, que primero el jazz (años 30 y 40 del siglo XX), y luego el rock (en líneas generales, el pop), parecen cumplir, aunque de manera banal y 'alienada', la función que le pedía a la música el Nietzsche-Dioniso (el seguidor de Wagner), pero, paradójicamente, a través del modelo que preconizaba el Nietzsche-Zaratustra (el enemigo de Wagner), como señala G. Morpurgo Tagliabue 4 ; dos, que, además de la función 'dionisíaca' de la moderna música de consumo en su conjunto, hay una parte de ella que pretende inscribirse explícitamente en la 'tradición' nietzscheana, incluyéndola como pensamiento 'profético' de un regreso a los cultos paganos nórdicos: así, podemos leer y oír sobre «Odinism in contemporary metal music», junto $\mathrm{a}$ «Nietzsche, père de la Renaissance traditionnelle Indo-Européenne» 5 . Se trata de la religión neo-pagana llamada Ásatrú, basada en el culto a los Aesir (Ases), dioses mayores de la mitología nórdica que habitaban el fabuloso Asgard.

Esos distintos aspectos de la 'música de hoy' nos llevan al corazón mismo de unas preguntas que deben formularse así: ¿Qué relaciones hay entre la música contemporánea y el pensamiento de Nietzsche? ¿Cuáles de ellas pueden ser consideradas 'legítimas' o 'genuinas', y cuáles 'manipuladoras' o falsificadas'? Pues bien: ese corazón, ese núcleo central desde el que se puede afrontar esas preguntas, no es otro que el designado en el título como un pensar por venir. Ya que eso es el pensamiento de Nietzsche: algo que ha sido formulado en palabras que conservamos escritas, pero que espera aún la interpretación, la

3 G. Morpurgo Tagliabue, «Después de Nietzsche», Archipiélago, 32 (1998), p. 15.

4 Ibid., pp. 16-17.

5 Noticias instaladas en los modernos medios de comunicación: ver en Internet www.hymninocturnales.com/bulletin_fevrier_2002. 
conquista de su sentido, no unívoco (pues eso es imposible para todo pensar 'activo') pero sí lo suficientemente comprehensivo y pleno, aunque provisional (como ha sucedido ya con otros pensadores, mientras que en el caso de Nietzsche es, en su mayor parte, todavía una tarea de futuro).

Esa tarea de futuro tiene, ya, algunos pasos dados. Pero probablemente la mayor parte de esos pasos haya consistido, y deba consistir aún, en una pars destruens propedéutica: determinar qué interpretaciones de Nietzsche son manipuladoras y falsificadas, $o$, aunque de buena fe, simplemente inadmisibles dentro de la diversidad hermenéutica legitimada por las investigaciones nietzscheanas rigurosas. En esta línea, parece que la apropiación nazi-fascista de Nietzsche es desechable sin más; pero no sólo en su forma histórica del III Reich o del fascismo mussoliniano y similares, sino en su forma más insidiosa de las representaciones y compulsiones sociales que inundan nuestro mundo, desde los mismos centros del poder (como Kraft, no como Macht) auxiliados por tantos de nosotros, sus servidores, inadvertidos o no. Por eso merece la pena detenerse un momento en el artículo «Después de Nietzsche» de G. Morpurgo Tagliabue, publicado en Archipiélagob.

En ese breve trabajo, el autor, como hemos indicado más arriba, partiendo de la distinción entre el 'Nietzsche joven' (el de Basilea, amigo de Wagner, Nietzsche-Dioniso), y el 'Nietzsche maduro' (el, in extremis, de Turín, enemigo de Wagner, Nietzsche-Zaratustra), muestra su parecer de que Nietzsche, en el ámbito de la 'música culta' sufre lo que Morpurgo Tagliabue llama una derrota-victoria [subrayado nuestro]: «¡Cuánto de Wagner queda, indeleble, en esta música, y qué derrota para Nietzsche! Pero, también, ¡cuánto de Zaratustra, cuánta ironía en la producción y en la recepción, qué victoria para Nietzsche!» 7 . Por el contrario, este autor afirma que, en el campo de la 'música de consumo', Nietzsche ha experimentado una victoria-derrota [subrayado nuestro]: «el arte anti-Wagner debía ser laico, optimista, no confesional, ni siquiera remotamente teológico o metafísico, un arte del hombre libre». Y es en la 'música de consumo' donde

6 Citado en nota 3.

7 Ibid., p. 15. 
se lleva a cabo el arte zaratustriano del último Nietzsche, aunque bajo las formas musicales dionisíacas del primer Nietzsche: «Sí, la música pop, rock, jazz, no es 'representativa' y tiene un componente irónico, es escarnecedora, optimista, enérgica, no es consoladora, elegíaca ni romántica; es danza, diversión: todos los requisitos que el último Nietzsche buscaba y no encontraba» 8 .

Morpurgo Tagliabue concluye que esa doble presencia de Nietzsche entre nosotros (la 'derrota-victoria' y la 'victoria-derrota'), cada una contradicha por la otra, prueba «hasta qué punto está Nietzsche vivo y presente, puesto que nuestra cultura actual es precisamente una cultura de vencedores vencidos». Mas para llegar a esta conclusión, más bien resignada, el autor ha necesitado introducir un dato exógeno, «una razón trivial, de hecho, histórica», como él mismo la llama ${ }^{9}$, que escapa a la previsión del pensar nietzscheano: «entre el mundo musical en el que se movía Nietzsche y nosotros se ha interpuesto un factor por aquel entonces imprevisible: la irrupción en el gusto del arte occidental de los modelos del Tercer Mundo, de lo exótico en la música de las masas» 10 , especialmente — dirá más adelante- «por tortuosos caminos, de África».

Es decir: «las discotecas como santuarios del atontamiento, de la droga musical [...]: un peligroso éxtasis de tres al cuarto», como el mismo autor gusta de decir, ;tienen su origen y su causa en los modelos musicales del Tercer Mundo, especialmente de África! Bizarra afirmación, tras la que se esconde una espesa capa de ágnoia duplós: ignorancia reduplicada en cuanto a resolver la dialéctica interna del pensamiento nietzscheano mediante un recurso extrínseco ad hoc; y en cuanto a desconocer que los modelos musicales extraeuropeos han supuesto, por el contrario, un poderoso elemento de renovación de la música occidental, justamente en el espíritu del pensar de Nietzsche: así, los gamelanes de Java y Bali en la música de Debussy (que los conoció en la Exposición de Paris de 1889), o las influencias asiáticas o africanas que impregnan, en buena parte, a gran número de los más significativos compositores contemporáneos: Olivier Messiaen, John Cage, Giacinto Scelsi y tantos más. 
Nos hemos detenido un poco en el escrito de Morpurgo Tagliabue, porque es una excelente muestra de 'interpretación' ciega ante el pensar nietzscheano y su carácter radicalmente libre. Hay una piedra de toque ante todo pensamiento liberador, que no es precisamente la de sufrir el ataque de las culturas extraeuropeas. Es precisamente Europa, o, más propiamente, su versión ampliada y pervertida llamada Occidente (que ya se extiende por zonas incluso del Oriente Lejano sometidas al imperio del Gran Hermano americano-multinacional) quien ha tratado y sigue tratando de impedir el afloramiento de cualquier pensar liberador. $Y$ lo hace de dos modos: o sojuzgándolo mediante la prohibición, $o$, más astutamente, absorbiéndolo mediante su degradación a instrumento cultural de dominación de las conciencias (es decir, mediante la masificación cualitativa): lo que llamamos 'productos de consumo', o, en el terreno de la cultura, 'bienes culturales' (que, sarcásticamente, ni son 'bienes' ni 'culturales'), resultan ser el resultado de un doble proceso de producción que se retroalimenta mutuamente: la producción de consumidores de estupidez, y la producción de estupidez para consumidores.

Al lado de ese 'dionisismo de masas' nacido en las raíces podridas (que ahogan cada vez más las que un día pudieron ser sanas) del fetiche que Occidente llama exultantemente 'democracia', casi es cosa de broma (pues aunque persigue el mismo fin, al menos no lo disimula), la existencia de los movimientos de la religiosidad nórdica neopagana, de representaciones tan toscamente elementales como la del joven SS que, en el III Reich, se creía trasunto del Übermensch: grupos musicales con nombres como 'Waldgeist', 'Darkwood', 'Storm', o incluso 'Asgard' (la morada de los dioses mayores nórdicos) se remiten a Nietzsche (al todavía wagneriano) diciendo de él cosas como esta: «l'apport de Nietzsche a constitué une authentique renaissance de l'esprit ancestral de l'Europe profonde» 11 . Hemos dicho 'casi es cosa de broma'. Solo 'casi': no se sabe qué es peor, si la extrema derecha que proclama claramente sus bárbaras pretensiones, o la derecha (y no solo la explícita) que dice contrarrestar a aquella, mediante el procedimiento de asumir sus mismos planteamientos con modales más suaves. 
Así las cosas, se puede afirmar que la única relación fecunda que puede darse entre 'Nietzsche' y 'la música de nuestro tiempo' necesita tener, como polos irreemplazables, estos dos: las interpretaciones rigurosas y contrastadas sobre Nietzsche, y la música 'culta', resultado conjunto del dominio técnico del material sonoro y de la reflexión sobre el fondo poético-pensante de donde surge toda obra de arte. Pues, si no es concebible un Nietzsche popularizado como 'bien cultural de consumo' (ya él mismo se encargó de decir algo al respecto en Sobre el porvenir de nuestras instituciones educativas), el correlato, la música, eo ipso, tampoco puede servir como el otro término de la relación bajo la especie de 'música de consumo'.

De hecho, la música contemporánea, 'la respiración musical de nuestro tiempo', comparte con el pensamiento nietzscheano la característica de abrirse paso con dificultad y de ser, todavía, en su más genuino sentido, asunto de minorías (por el esfuerzo que representa penetrar en ambos, pues si bien la recompensa es alta, la trivialización del consumo fácil incita a gustar de la basura, con tal de que se adquiera con nula fatiga). Desde esa perspectiva, toda la música de nuestro tiempo, es música 'por venir', igual que el pensamiento de Nietzsche, $y$, en ese sentido genérico, toda ella es 'nietzscheana'.

Mónica B. Cragnolini, en su artículo «Música y filosofía en el pensamiento nietzscheano: sobre entrecruzamientos y tensiones» 12 , describe tres modos de relacionar a Nietzsche con la música ('culta', por supuesto), a los que llama (musicalmente) «resonancias»: primera, «Nietzsche como amante de la música»; segunda, «Nietzsche como músico y los músicos 'nietzscheanos'»; tercera, «filosofía y música».

En la primera 'resonancia', son sobradamente conocidas la historia y las razones de su amor y su desamor hacia Wagner; la pretendida vuelta a Mozart, o el aprecio a Carmen, a Rossini, a las operetas y, en lo que a la música española se refiere, a las zarzuelas de Ruperto Chapí, en cuanto antídotos antiwagnerianos. Más allá de aspectos algo sorprendentes que se puedan señalar, como la alusión a «la música de mi maestro veneciano Pietro Gasti»13 (italianización del apodo que Nietzsche daba a su amanuense Köselitz), la propuesta nietzscheana de la ligereza y la mediterraneidad, el juego de estructurar y deses-

12 En Jornadas Nietzsche 1998, localizado en www.nietzscheana.com.ar.

13 Nietzsche contra Wagner, KSA 6, p. 420 
tructurar, al modo de la filosofía de «las pompas de jabón» a la que se refiere Zaratustra, tendrán, como veremos, influencia en algunos compositores posteriores.

De la segunda relación de Nietzsche con la música, «Nietzsche como músico y los músicos 'nietzscheanos'», nos interesa aquí la segunda parte: los compositores inspirados en Nietzsche. Claro que la inspiración, en este caso, no proviene de las composiciones de Nietzsche, sino de sus escritos. Cristóbal Halffter ${ }^{14}$, al mismo tiempo que destaca «la imaginación y la fantasía» de Nietzsche, así como «su extraordinaria capacidad de improvisación..., que rozaba la genialidad», señala que, como compositor, carecía del dominio continuado de las técnicas compositivas, que son las únicas capaces, más allá del instante de la intuición y la improvisación, de constituir una obra de arte musical (nos preguntamos, al leer eso, si Nietzsche no hubiera podido ser, en el lugar y el tiempo adecuados, un excepcional jazzista). Pero Halffter va más lejos: respecto al pensamiento explícitamente musical, llega a decir, considerando la 'crítica feroz' a Wagner y el silencio sobre Debussy, que «Nietzsche es un pensador sugerente, imaginativo y atractivo; un creador no sistemático, fragmentario y contradictorio, al menos en lo que se refleja en sus escritos sobre la creación musical que se estaba realizando en su entorno» 15 . En cualquier caso, esto nos aboca a la tercera relación o 'resonancia': filosofía y música. La influencia esencial de Nietzsche en los compositores posteriores se ejerce desde su filosofía, bien que se trate de su 'filosofía de la música', bien de toda su filosofía. Sin desdeñar el papel del Nietzsche poeta, ya que cabe preguntarse si los numerosos poemas o fragmentos suyos que han sido musicados en forma de Lieder, lo han sido únicamente por su calidad poética (como, por ejemplo, en el caso de Goethe o Hölderlin), o por ser 'espejos' en los que se refleja la totalidad de su pensamiento.

De un modo o de otro, más de un centenar de compositores han incluido a Nietzsche, de una manera u otra, en sus obras ${ }^{16}$. Si empe-

14 Suplemento ElCultural, www.elcultural.es/Especial/Nietzsche.

15 El reproche por el silencio sobre el Debussy anterior a 1894 (más aún, anterior a enero de 1889) no está justificado: ¿qué obras verdaderamente ‘debussyanas' se habían estrenado antes de esa fecha?

16 Transcribimos la nota 9 de Cragnolini en el artículo antes citado: «La fuente ineludible para este tema es D. Tachter, «Musical settings of Nietzsche text. An annoted 
zamos por lo más sencillo, debemos tomar en cuenta, en primer lugar, los textos (poemas o fragmentos) nietzscheanos que han sido convertidos en la letra de composiciones vocales o vocal-instrumentales; 'Canciones', Songs o Lieder. Como en la nota anterior se da la fuente para localizar estas composiciones textuales, nos limitaremos aquí a reseñar algunos ejemplos significativos.

Dicho esto, son destacables, en primer lugar, los Lieder de Nikolai Karlovitch Medtner (1880-1951). Este compositor y pianista ruso, que vivió fuera de su país desde 1921 y murió en Londres, se caracterizó por crear casi exclusivamente música para piano o para voz y piano. Aparte de dos largos ciclos sobre poemas de Goethe y otros sobre diversos autores, compuso cinco canciones sobre textos de Nietzsche: las op. 19, $\mathrm{n}^{\circ}$ 1, 2, 3 (Gruss, Alt Mütterlein, Heimweh), y las op. 19a, $\mathrm{n}^{\circ}$ 1, 2 (Heimkehr, Verzweiflung), todas ellas traducidas al ruso, pero cantables en ambos idiomas. El estilo personal de Medtner, basado en los grandes clásicos, lleno de poesía y nobleza, no permite incluirlo, salvo con criterios meramente cronológicos, en la música contemporánea; pero es un testimonio de tal sinceridad y simpatía hacia Nietzsche, muy cercano a su muerte, que no resistimos mencionarlo aquí.

Junto a Medtner, pueden señalarse una serie de compositores menores que han compuesto canciones o Lieder sobre textos de Nietzsche Así, Felix Wolfes (1892-1971), puso música en 1961 a «Venedig»y a «O Mensch! Gibt Acht!» (bajo el título Das trunkene Lied); Lukas Foss (1922-), en 1959-60, a ese último texto (que no es otro que el célebre «Mitternachtslied» del Zaratustra, el cual aparece también, en amplias y famosas composiciones de Mahler y Delius, de las que nos ocuparemos más adelante).

La relación de compositores de Lieder sobre textos de Nietzsche es mucho más extensa: entre los compositores 'menores', además de los citados, podríamos añadir a Ernest Vietor (fl. 1905-1930), Ernst Pepping (1901-1981), Kurt Thomas (1904-1973) o Richard Trunk (1879-1978).

bibliography», I, II, y III, en Nietzsche Studien (en adelante, NS) 4 (1975), pp. 284-323; NS 5 (1976), pp. 355-383; y NS 15 (1986), pp. 440-452, respectivamente». Pero la 'ineludibilidad' de esta fuente está sometida a dos limitaciones: a) que sólo alcanza hasta 1986; y b) que como indica el título, se reduce a la puesta en música de textos de Nietzsche. La influencia de Nietzsche en la composición musical del ultimo siglo es mucho mayor que sólo eso. 
También algunos compositores famosos han compuesto algún Lied ocasional sobre textos nietzscheanos. Así, Der Wanderer, op. 6 n 8 de Schönberg (1874-1951), compuesto en 1905; o Anton Webern (18831945), uno de cuyos Acht frühe Lieder (1901-1904) es Heiter (el n $\left.{ }^{\circ} 6\right)$, sobre el poema de Nietzsche «Mein Herz ist wie ein See so weit», al cual también pone música, en 1919, Carl Orff(1895-1982).

Orff, en cierto sentido, no puede considerarse sólo como un 'liederista' nietzscheano circunstancial, si tenemos en cuenta que, en 1912, cuando contaba sólo 17 años, compuso su primera obra coral extensa, Also sprach Zarathustra, aunque de valor musical no especialmente apreciable.

Quienes, desde luego, tienen un interés por Nietzsche que sobrepasa la composición de unos Lieder más o menos misceláneos son Delius y Hindemith. Frederick Delius (1862-1934), aparte de su gran obra nietzscheana, de la que nos ocuparemos después, compone en 1898 Der Einsame, Der Wanderer, Der Wanderer und sein Schatten y Nach neuen Meeren; así como el Zarathustras Mitternachtslied para barítono, coro masculino y orquesta. Por su parte, de Paul Hindemith (1895-1963), además de la ópera que mencionaremos después, son los Liedernach Texten von Friedrich Nietzsche, I: Unter Feinden; II: Die Sonne sinkt, compuestos en 1939, el mismo año que Nun da der Tag des tages müde war, de Drei Chöre, núm. 2.

Pero es en las grandes obras (grandes por su extensión y por su maestría) donde la relación entre Nietzsche y la música del último siglo se muestra de la manera más relevante y profunda.

En un Seminario impartido en la Universidad de Frankfurt a. M. durante el semestre de verano de 2001, bajo el título Das Dionysische in den Musikdramen des Fin de sièclel7, Wolfgang Krebs distribuye las grandes composiciones de inspiración nietzscheana en varios grupos:

$1^{\circ}$ Las inaugurales, en la que se manifiesta todo el esplendor de lo dionisíaco: Tercera Sinfonía de Mahler, Una misa de la vida de Delius, y Así babló Zaratustra y la Sinfonía alpina de R. Strauss;

$2^{\circ}$ las que parangonan la décadencey la condición dionisíaca: las óperas Saloméy Elektra de R. Strauss;

$3^{\circ}$ el 'renacimiento' de Dioniso: Violanta, ópera de Korngold;

17 Cf. www.rz.uni-frankfurt.de/ wkrebs/Sem. 
$4^{\circ}$ lo dionisíaco como 'romántico': Romeo und Julia auf dem Dorfe de Delius, Das Wunder der Heliane de Korngold (óperas);

$5^{\circ}$ Dioniso como Anticristo: las óperas Sancta Susana de Hindemith, y Krol Roger (en polaco) de Szymanowski;

$6^{\circ}$ Lo dionisíaco y el élan vital: la ópera Ariadne auf $N$ axos de R. Strauss;

$7^{\circ} \ll$ Krankheit und Übermenschentum im dionysischen Kontext» 18: Die Gezeichneten (Los dados marcados) de Franz Schreker (ópera).

$8^{\circ}$ Lo apolíneo y lo dionisíaco: Daphne, ópera de R. Strauss.

A esta relación sobre las composiciones mayores del último siglo, hay que añadir, por su interés desde el punto de vista de la innovación técnico-musical, algunas obras del microtonalista Ivan Wyschnegradsky (1893-1979) tales como Cycle de chants sur Nietzsche (canto y piano), y Ainsiparlait Zarathoustra (cuatro pianos), en cuartos de tono 19. Pero, sobre todo, no se puede ignorar la obra maestra de Vagn Holmboe, uno de los más grandes compositores daneses del siglo XX: la cantata Requiem for Nietzsche (el for, como toda la obra, es en danés).

Como se ve, Richard Strauss (1864-1949) es quien aparece en más ocasiones: el poema sinfónico op. 30 Also sprach Zarathustra (1896), «compuesto libremente a partir de Friedrich Nietzsche», la obra, entre sinfonía y poema sinfónico, Eine Alpensymphonie op. 64 (1915), y las óperas Saloméop. 54 (1905), Elektra op. 58 (1909), Ariadne auf Naxos op. 60 (1912) y Daphne op. 82 (1937). Pero, salvo esta mención, no nos ocuparemos de él expresamente: sus obras son sobrada-

18 Preferimos dejarlo en alemán sin traducirlo: se entiende mejor Übermenschentum que 'sobrehumanidad', 'condición de sobrehumano' u otra versión semejante.

19 Este compositor ruso, que estudió en el Conservatorio de San Petersburgo, se estableció en Paris desde 1920. Trabajó por una escala musical con divisiones menores del semitono (cuartos, sextos y doceavos). Defendió, en el plano teórico, su propuesta en su Manuel d'harmonie. En la práctica trabajó, en colaboración con el compositor checo Alois Hába (1893-1973) en la construcción de un piano adecuado para estos intervalos, que, finalmente construyó la firma Pleyel, con dos teclados, para producir cuartos de tono. Lamentablemente, hay referencias discográficas de pocas obras suyas, entre las que sólo se encuentran Deux chants sur Nietzsche op. 9, en I. A. Wyschnegradsky, Dialogue. Ensemble 2E2M. Dir: Paul Mefano. 2e2m Records \#1001. 
mente conocidas, y las referencias discográficas son, casi todas, numerosas y fáciles de localizar.

Sí es interesante, aunque también sea muy conocida, hacer referencia a la inclusión del «Zarathustras Mitternachtslied» (O Mensch! Gibt Acht.) en la Tercera Sinfonía, en re menor (acabada en 1896) de Mahler (1860-1911). Las palabras del compositor, cuando estaba plenamente ocupado en la escritura de la Tercera, en el verano de 1895, son reveladoras del estado de su espíritu en esos momentos: «el término sinfonía significa para mí construir un mundo utilizando todos los medios técnicos a mi disposición». Es decir, Mahler se considera un demiurgo, un intermediario entre la divinidad y los hombres, una especie de Sumo Sacerdote laico. En ese contexto, adquiere su pleno significado la inclusión de la Canción de medianoche de Zaratustra. en ese cuarto movimiento de los seis que constituyen la obra ¿ Acaso el propio Nietzsche no había designado al Zaratustra como una 'sinfonía’? Mahler, al introducir el «Mitternachtslied», se identifica de algún modo con el Nietzsche-Zaratustra, y esto en 1895, cuando todavía estaba el filósofo físicamente vivo, aunque sumido en las sombras.

Así como la influencia de Nietzsche en Richard Strauss se ha querido interpretar concomitantemente con las simpatías de Strauss hacia el régimen hitleriano (cuestión sobre la que habría que hilar fino, sobre todo teniendo en cuenta el alejamiento producido a partir de 1937, cuando a raíz del estreno de Dieschweigsame Frau, Strauss defendió con valentía inequívoca a su libretista, el judío Stefan Zweig), la pretensión de acercar a Nietzsche y al nazismo 20 tropieza, aquí mismo, con unos contraejemplos contundentes: Franz Schreker (1878-1934) y Erich Wolfgang Korngold (1897-1957) ven clasificadas rápidamente sus obras bajo la etiqueta de entartete Musik, 'música degenerada', con la que los propagandistas nazis designaron la música atonal, los arreglos de jazz y, sobre todo, la música de los compositores judíos ${ }^{21}$. Por otra parte,

20 Esa pretensión también se da en el caso de Carl Orff: y aunque el 'nietzcheanismo' de Orff es casi inexistente, no lo son sus simpatías pro-nazis. Al fin y al cabo, fue a Orff y no a Strauss, compositor infinitamente superior, a quien el régimen encargó el himno de los Juegos Olímpicos de 1936 en Berlín... aunque luego la RFA le encargó también, en 1972, el himno de los Juegos Olímpicos de Munich...

21 El término 'degenerado' lo tomaron los nazis de Cesare Lombroso, que se refiere con él a la 'anormalidad' (entendida como 'deterioro'). Este sentido de 'anormalidad' no sería aceptado hoy por muchos psiquiatras y psicólogos. 
Hindemith, autor de la ópera Sancta Susana (1921), tercera de la trilogía cuyas dos anteriores fueron Morder, Hoffnung der Fragüen (1919) y Das Nusch-Nuschi(1920), sufrió el escándalo público cuando se produjo en 1934 el estreno de la sinfonía Matías el Pintor, y a partir de entonces solo pudo soportar su estancia (aunque intermitente) en Alemania hasta 193722 .

Terminaremos esta breve aproximación haciendo una referencia algo más amplia a tres composiciones capitales (de sus autores, y de toda la música del siglo $\mathrm{XX}$ ) relacionadas intensa y hondamente con Nietzsche, $y$, nos tememos, casi completamente desconocidas salvo para los especialistas y raros devotos de la música del último siglo: Eine Messe des Lebens de Delius, Król Roger de Szymanowski, y Requiem for Nietzsche de Holmboe.

Frederick Delius, nacido británico (aunque de origen alemán), y muerto en Francia, en su retiro de Grez-sur-Loing, es casi exacto contemporáneo de Debussy (nacieron el mismo año de 1862, aunque Delius sobrevivió a Debussy desde 1918 a 1934, si bien en sus últimos años se absorbió en la contemplación de la naturaleza y su producción musical es escasa). Ambos comparten una concepción hedonista e instintiva de su arte, basada en la búsqueda del color armónico y tímbrico, al igual que un 'panteísmo' (no religioso, sino volcado hacia la naturaleza). Con todas las reservas que exigen estas categorizaciones, Delius, junto con Debussy y Ravel, es uno de los mayores representantes de lo que se ha llamado el 'impresionismo musical'. Con todo, en Francia, donde vivió la mayor parte de su vida, se sigue ignorando a este apátrida (eso puede explicar, en alguna medida, su desconocimiento en España), que, sin embargo se conoce ampliamen-

22 Las cuatro óperas aludidas, si no obras maestras como las tres obras que se tratan a continuación, merecen ser oídas, tanto por su calidad musical como por rendir un homenaje al arte prohibido por la barbarie. P. Hindemith, Sancta Susanna. Drei Gesänge, Radio-SinfonieOrchester Berlin, G. Albrecht, Wergo, la grabación original es de 1996, pero ha aparecido de nuevo en junio de 2002, 1 cd. E. W. Korngold, Violanta, E. Marton, W. Berry, S. Jerusalem et. al., Bayerischen Rundfunkorchester, M. Janowski, Sony \#35909, 1 cd. E. W. Korngold, Das Wunder der Heliane, A. Tomowa-Sintow, H. Welker et. al., Berlin Radio Chorus, Berlin Radio Symphony Orchestra, J. Mauceri, Decca (col. «Entartete Musik») E4366362, 3 cd. F. Schreker, Die Gezeichneten, A. Muff, M. Pederson, J. Becker, Christiane Berggold et. al., Berlin Radio Chorus, Berlin Deutsches Radio Symphony Orchestra, L. Zagrosek, Decca (col. «Entartete Musik») E4444422, 3 cd. 
te en Alemania y en los países anglosajones; gracias, sobre todo, al 'apostolado' infatigable del director de orquesta sir Thomas Beecham (que fue para Delius lo que Max Brod para Kafka y para Janácek), tarea en la que lo sucedió la siguiente generación de jóvenes directores anglo-germánicos.

A Mass of Life (Una misa de la vida): título en ingles, aunque con la indicación Sung in German, por lo que su nombre más propio debe ser Eine Messe des Lebens, fue concluida en 1905, y estrenada en su versión íntegra en 1909, en Londres, precisamente por Thomas Beecham ${ }^{23}$. Delius había descubierto por casualidad la obra de Nietzsche en su juventud: «cuando, un día de lluvia... buscando algo para leer en la biblioteca de un amigo noruego, en cuya casa se hospedaba, descubrió un libro, Así habló Zaratustra... escrito por un tal Friedrich Nietzsche, él [Delius] estaba maduro para leerlo. Este libro, me dijo, no lo puedo soltar hasta haberlo devorado de punta a cabo. Ese era el libro que había buscado desde siempre... Y a partir de ahí, no dejó de leer todas las obras de Nietzsche que encontró a su alcance»24. La lectura del Zaratustra (y de las otras obras) produjo en Delius el efecto de una embriaguez dionisíaca, pero también la conciencia del carácter efímero de la belleza, del amor, del hombre. Nietzsche le conforta en su paganismo, en su fe exclusiva en el hombre, en su voluntad de realización como artista. El texto de $A$ Mass of Life fue seleccionado a partir del Zaratustra en 1904 por Delius y un joven director de orquesta alemán, Fritz Cassirer, a quien dedicó la composición. «Sería incluso posible considerar a Zaratustra como una composición musical, una sinfonía», había escrito Nietzsche. Pues bien: «ningún otro músico estaba, sin duda, más predestinado que Delius para dar a las metáforas nietzscheanas un equivalente sonoro. Y fue más el trato continuado con el vasto poema alegórico nietzscheano

23 Aunque mencionaremos después una grabación más reciente y de gran calidad artística y técnica, hay una grabación histórica (recientemente reeditada) dirigida por el propio Beecham, naturalmente muchos años después del estreno de 1909: Beecham Conducts Delius ( $A$ Mass of Life). Contiene, en primer lugar, una introducción, en inglés, en voz de Beecham sobre Delius y A Mass of Life, y luego la interpretación de «A Mass of Life: Deutsche Fassung», a cargo de R. Raisbeck, M. Sinclair, Ch. Craig y B. Boyce, London Philharmonic Choir, Royal Philharmonic Orchestra London, Thomas Beecham, Sony Classical, 2 cd.

24 Así lo cuenta Eric Fenby, secretario del compositor. 
que el deseo de rivalizar con Strauss, cuyo poema sinfónico había visto la luz en 1896, lo que hizo madurar el proyecto. La composición de este oratorio colosal, intermitente, duró cerca de diez años» 25 . Una misa de la vida, la más ambiciosa de todas las obras de Delius, construye una 'atmósfera' singular, inigualable: porque «la poesía llena de éxtasis de Nietzsche encuentra un complemento ideal en la belleza hipnótica y el ardor exaltado de la música» (Philip Borg-Wheeler). Dividida en dos partes, con once secciones (cinco y seis), su audición constituye, sin ninguna duda, una experiencia excepcional de placer, de conocimiento, y de comprensión y reflexión sobre la obra de Nietzsche26.

Así como la obra maestra que es $A$ Mass of Life significa el nietzscheanismo apasionado, la ebriedad dionisíaca y el entusiasmo poético, otra de las mayores composiciones del Siglo XX, la ópera Król Roger(ElRey Roger) op. 46, del polaco Karol Szymanowski (18821937 ) es un prodigio de sutileza, donde se emplea con maestría inigualable el juego de la 'contradicción' entre lo dionisíaco y el cristianismo, hasta unos extremos de ambigüedad que reflejan la que también existe entre una interpretación que no sea apresurada y contundente del 'Anticristo' y esa enigmática afirmación de los Póstumos que dice: «Hay en mí algo de hipercristiano».

Si aceptamos la afirmación de que «del mismo modo que ninguna música se parece verdaderamente a la de Szymanowski, ninguna ópera se parece a ElRey Rogers (Andrew Huth), tendremos una clave para entender su relación con Nietzsche. Porque, podemos añadir, tampoco ningún pensador se parece verdaderamente a Friedrich Nietzsche. Con una sensibilidad particularísima, en un período de crisis, tanto de la cultura europea como personal, estaópera pone en escena una versión original del conflicto secular entre Apolo y Dioniso, entre las fuerzas de la razón, por un lado, y, por otro, las del instinto, el inconsciente y la sexualidad (se insinúa en el fondo de la trama un desvelamiento

25 F.-R. Tranchefort (ed), La musique sacrée et chorale profane. De 1750 à nous jours. Fayard, Paris, 1993, pp. 223-224.

26 Aparte de la grabación histórica dirigida por Beecham (nota 23), recomendamos ésta, excepcional (artística y técnicamente): F. Delius, Requiem. A Mass of Life (Sung in German), R. Evans, J. Rodgers, J. Rigby, N. Robson, P. Coleman-Wright, Bournemouth Symphony Chorus, Bournemouth Symphony Orchestra, R. Hickox, Chandos CHAN 9515(2), 2 cd. 
del amor homosexual siempre latente, pero de un modo exquisito y levemente insinuado, en el autor; incluso la proximidad entre su nombre, Karol, y Król, 'rey' en polaco, es una especie de clave).

Szymanowski pertenecía a una familia polaca: creció en Tymoszówka, propiedad que ésta poseía en Ucrania, entonces parte integrante de Rusia. El medio aristocrático y cultivado a que pertenecía practicaba la música y la literatura con fervorosa pasión; de modo que cuando Karol fue a estudiar a Varsovia tropezó con lo que le pareció estrecho provincianismo polaco. Eso le impulsó a viajar a Europa del Oeste, especialmente a Alemania; pero su plena madurez artística la adquirió tras sus viajes por el Mediterráneo (años 1908-1914). Sus impresiones de Italia, de Sicilia y del Norte de África, aumentan la sensualidad de su arte y, a la vez, le acarrean una pérdida de interés por los modelos culturales germánicos.

La ópera, que está cantada en polaco, fue esbozada a partir de 1918 , en colaboración con su joven pariente y amigo el poeta Jaroslaw Iwaszkiewicz (1894-1980); pero más tarde su primo se desinteresó de la colaboración, y Szymanowski reescribió una gran parte del texto.

El amor por el Sur y el profundo conocimiento de la historia de los países mediterráneos determinarán el tiempo y el lugar de la ópera: la Sicilia del siglo XII, donde se entrecruzan lenguas, culturas y religiones, de Oriente y Occidente, de Norte y Sur, de la Antigüedad y la Edad Media, de Roma y Bizancio, del Cristianismo y el Islam. Los personajes principales son el pastor-profeta, la reina Roxana, dominada por el instinto y la pasión (muestra de 'dionisismo' elemental), Edrisi, el sabio consejero musulmán, que representa la voz calma de la razón, 'apolínea'; y claro, el rey Roger, en el que se reúnen todos los elementos del conflicto, de la tensión siempre irresuelta entre razón y sensualidad (y por lo mismo, la única 'viva', dionisíaco-apolínea, nietzscheana).

Los lugares y momentos donde se desarrollan los tres actos (la catedral iluminada a la caída de la tarde; el palacio a media noche; las ruinas de un teatro griego iluminado por la luna en la alta noche y la aurora: la acción se extiende desde el atardecer hasta el amanecer del día siguiente), los cambios que se realizan en los personajes, el ambiguo final en el que Roger elige la luz del sol, pero entonces es cuando nos parece que lo más dionisíaco es lo apolíneo, y lo más apolíneo lo dionisíaco...; todo, envuelto en una música de un deslumbrante refi- 
namiento tímbrico, contribuye a la consagración de Król Roger como una de las más grandes óperas del siglo XX, y probablemente, la obra musical más compleja, poliédrica y entrecruzadamente nietzscheana de la que tenemos noticia hasta hoy 27.

Y para (casi) concluir, una obra, aunque compuesta en 1963-64, recién sacada del horno (grabada a finales de agosto de 2001, y aparecida el 13 de mayo de 2002, lo que significa que, fuera de Dinamarca y algún otro lugar privilegiado, no se había oído nunca): la cantata en lengua danesa Requiem for Nietzsche de Holmboe 28.

Vagn Holmboe (1909-1996) es, probablemente, el más conocido compositor danés después de Carl Nielsen (1865-1931). Así pues, ocupa el lugar más distinguido en la música danesa durante los dos últimos tercios del siglo XX. Su producción se cifra en torno a las 400 obras, especialmente de música orquestal, de cámara y coral. Fue profesor en el Real Conservatorio Danés de Copenhague hasta 1965, año en que se retiró para dedicarse exclusivamente a la composición. Su música tiene influencias de Nielsen, Sibelius y Stravinski, y también se interesó por el folclore danés. En todo caso, el resultado es que su música se caracteriza por una comprometida integridad y una originalidad refinada; al mismo tiempo poderosa y sutil, disciplinada y apasionada, penetra profundamente en el drama humano.

Holmboe compuso el Requiem for Nietscheop. 84 en los años 19631964. Escrito para barítono, tenor, coro y gran orquesta, pertenece a la misma época de varias de sus obras mayores. El origen de esta obra se debe a una afortunada circunstancia: con motivo de la interpretación en la Universidad de Aarhus de unas cantatas que le fueron encargadas por esa institución, conoció a uno de los más distinguidos poetas daneses, Thorkild Bjørnvig (n. 1918). Ambos artistas descubrieron pronto que se establecía entre ambos una aguda y profunda comunicación, además de otras similitudes intelectuales. Bjørnvig ha-

27 De las varias grabaciones que hay de ElRey Roger, la versión de referencia, sin duda, es: K. Szymanowski, King Roger (en polaco) / Symphony No. 4. Thomas Hampson, Elzbieta Szmytka et. Al. City of Birmingham Symphony Chorus. City of Birmingham Symphony Youth Chorus. City of Birmingham Symphony Orchestra. Dir. Sir Simon Rattle. EMI Classics, 556823 2. 2 CD.

28 V. Holmboe, Requiem for Nietzsche (en danés). Helge Rønning, tenor; Johan Reuter, baritone. Danish National Symphony Orchestra and Choir. Dir. Michael Schønwandt. Dacapo 8.224207 . 
bía publicado, en 1959, una colección de poemas titulada Figur og Ild (Figura y fuego), que incluía, bajo el simple título de «Nietzsche», un ciclo de once sonetos, que él mismo sugirió que podrían ser puestos en música por Holmboe, una música que sería un signo de verdad en una época de confusión, corrupción, e incluso maldad. Para Holmboe fue un reto que lo atrajo intensamente, ya que la desapasionada corrección formal de los sonetos contrastaba fuertemente con las fuertes imágenes y alusiones de su contenido, y eso se correspondía con su estilo y su ideario musical. Ciertamente, cada uno de ellos había encontrado, por su actitud creativa y su sensibilidad humana, en el otro a su espiritual alter ego.

Los sonetos contienen vívidamente acontecimientos e ideas de la vida de Nietzsche, bajo el modo de una interpretación simbólica de sus expectativas, aspiraciones, conflictos y trágico final. No se trata de una biografía de Nietzsche, incluso los poemas no se dan en orden cronológico; pero cada uno de ellos contiene algo así como un intento de comprensión total del filósofo, desde distintas perspectivas. Por eso, Holmboe titula al conjunto Requiem for Nietzsche. porque se trata de una rememoración, que trata de ser total en cada uno de sus momentos, de esa 'unidad de dispersiones' que constituyen el pensamiento y la vida nietzscheanos.

El Requiem está dividido en cinco partes. La primera comprende dos movimientos (cada movimiento corresponde a un soneto de Bjørnvig): 1. Preludio en el desierto, y 2. Basilea. La segunda, tres movimientos: 3. Los amigos, 4. Sils Maria, y 5. La tercera tentación. La tercera, otros tres movimientos: 6. El momento, 7. La canción de la góndola, y 8. Jena. La cuarta, dos movimientos: 9. Ecce Homo, y 10. Weimar. Finalmente, la Parte V comprende un solo movimiento: 11. Asgaardsreien, o sea La cabalgata de Asgard, la morada de los dioses nórdicos, recorrida por los cazadores salvajes pero benéficos a cuyo frente va el mismo Thor. El significado de cada uno de los movimientos es fuertemente simbólico y lleno de coimplicaciones: así, Preludio en el desierto hace referencia a la relación entre Jesús y Nietzsche-Zaratustra. Tanto la música como la letra ${ }^{29}$ son una excelente fuente de meditación nietzscheana, que compensará con creces al lector-oyente.

29 Aunque la letra de cada movimiento está en danés, en el libreto del CD figura la traducción en inglés y en alemán. 
Dejamos atrás algunas cuestiones que sería interesante tocar, aunque fuera de pasada: por ejemplo, la música empleada en la banda sonora de la obra cinematográfica de Stanley Kubrick, 2001, Una odisea del espacio; música que acompaña a imágenes también nietzscheanas (la elipsis más larga, cronológicamente, de la historia del cine, en el comienzo de la cinta; las imágenes luminosas abstractas producidas con un ingenioso juego de espejos; el simbolismo de la última parte, con aquellas escenas surrealistas, el monolito, el feto...); música explícitamente nietzscheana (Also sprach Zaratbustra de R. Strauss) junto con el contrapunto del Bello Danubio azul, y en medio, varias piezas, intensamente nietzscheanas, pero de modo implícito (Requiem, Lux aeterna, Atmosphères) de György Ligeti, tal vez el compositor vivo más importante.

Nietzsche había dicho ya: «Solamente a partir de la más alta fuerza del presente tendréis el derecho de interpretar el pasado» 30 . Con esta aproximación, hemos intentado mostrar que la música de hoy, con la fuerza del presente, se constituye, lo mismo que el pensamiento nietzscheano, en intérprete del pasado vivo; pero ese pasado vivo interpretado desde el presente, constituye a, y es constituido por -el pensar por venir. 